\title{
Seletividade e Controle de Plantas Daninhas com Oxyfluorfen e Sulfentrazone na Implantação de lavoura de CaFE ${ }^{1}$
}

\author{
Weed Selectivity and Control with Oxyfluorfen and Sulfentrazone in Young Arabica Coffee \\ Plantations
}

\author{
MAGALHÃES, C.E.O. ${ }^{2}$, RONCHI, C.P. ${ }^{3}$, RUAS, R.A.A. ${ }^{4}$, SILVA. M.A.A. ${ }^{2}$, ARAÚJO, F.C. ${ }^{2}$ e \\ ALMEIDA, W.L. ${ }^{2}$
}

\begin{abstract}
RESUMO - Este trabalho teve por objetivo avaliar a seletividade do oxyfluorfen e do sulfentrazone e o controle de plantas daninhas em diferentes épocas após o transplantio das mudas de café no campo. Foram realizados três ensaios no delineamento experimental de blocos casualizados com dez tratamentos e quatro repetições. No ensaio 1, aos 30 dias após o transplantio (DAT) e, no ensaio 2, aos 90 DAT, testaram-se duas doses de oxyfluorfen $(0,36$ e 0,72 kg i.a. ha-1) e de sulfentrazone (0,4 e 0,6 kg i.a. ha ${ }^{-1}$ ), em jato dirigido ao solo (com proteção das mudas) e em área total. No ensaio 3, os mesmos herbicidas e doses foram aplicados, porém aos 300 DAT e apenas em aplicação dirigida, testando-se duas pontas de pulverização de diferentes potenciais de deriva. Em todos os ensaios, acrescentaram-se as testemunhas capinada e sem capina. A entrelinha foi manejada com roçada. Foram identificadas as espécies de plantas daninhas e suas densidades. A eficácia dos herbicidas e suas seletividades também foram avaliadas. A principal planta daninha que ocorreu na área experimental foi Brachiaria decumbens. Sintomas visuais de toxicidade foram observados apenas quando os herbicidas foram aplicados em área total (ensaios 1 e 2), independentemente da dose e época de aplicação. No ensaio 3, independentemente do herbicida, da dose e da ponta utilizada, não houve sintomas visuais de toxicidade, nem redução no crescimento das plantas, em função da aplicação dirigida. Em todas as épocas o controle de plantas daninhas foi eficiente, porém a seletividade só foi alcançada na aplicação dirigida, para ambos os herbicidas.
\end{abstract}

Palavras-chave: Brachiaria decumbens, Coffea arabica, herbicidas, manejo integrado, tecnologia de aplicação.

\begin{abstract}
This study aimed to evaluate oxyfluorfen and sulfentrazone selectivity and weed control in young coffee plantations (Coffea arabica cv. Red Catuai). Three trials were conducted in a randomized complete block design, with 10 treatments and four replicates. In the first and second trials, at 30 and 90 days after transplanting (DAT), respectively, two doses of oxyfluorfen 10.36 and $0.72 \mathrm{~kg}$ a.i. $\left.\mathrm{ha}^{-1}\right)$ and sulfentrazone $(0.4$ and $0.6 \mathrm{~kg}$ a.i. ha-1) were tested by spraying the herbicides directly into soil (with seedling protection) or onto the total area. The same herbicides and doses were used in the third trial, but at 300 DAT and only directed to the soil, using two sprayer nozzles with different drift potentials being tested. Two additional control plots were added: handweeding control and weedy treatments. Weeds present in the inter-row spaces were eliminated by mowing operations. Weeds and their densities were identified. The toxicity of the herbicides to the coffee plants and its effectiveness in controlling the weeds were assessed. The main weed occurring in the experimental area was Brachiaria decumbens. Visual symptoms of herbicide toxicity were observed only when the herbicides were applied in the entire area (trials 1 and 2), regardless of their doses and application times. At the third herbicide application trial, no visual symptoms of herbicide toxicity and no reductions in plant growth were observed, regardless of the herbicide, the dose and the sprayer nozzles tested. At all times, a very good weed control percentage was obtained, but selectivity occurred only when the herbicides were not applied onto the total area.
\end{abstract}

Keywords: application technology, Brachiaria decumbens, Coffea arabica, herbicides, integrated weed management.

Recebido para publicação em 25.6.2011 e aprovado em 15.5.2012.

2 Graduando em Agronomia, Universidade Federal de Viçosa - Campus Rio Paranaíba - Rod BR 354, km 310, Caixa Postal 22, 38810-000, Rio Paranaíba-MG; ${ }^{3}$ Professor, Universidade Federal de Viçosa - Campus Rio Paranaíba - Rod BR 354, km 310, Caixa Postal 22, 38810-000, Rio Paranaíba-MG, <claudiopagotto@ufv.br>; ${ }^{4}$ Professor, Universidade Federal de Viçosa - Campus Rio Paranaíba - Rod BR 354, km 310, Caixa Postal 22, 38810-000, Rio Paranaíba-MG, <renatoruas@ufv.br>.

Planta Daninha, Viçosa-MG, v. 30, n. 3, p. 607-616, 2012 


\section{INTRODUÇÃO}

Dados oficiais do Instituto Brasileiro de Geografia e Estatística - IBGE apontam o café arábica como a cultura de maior importância para a região do Alto Paranaíba, seja por seu cultivo em $100 \%$ dos municípios da região, pelo alto valor econômico da produção ou pelo grande emprego de mão de obra. Em 2010, a região do Alto Paranaíba, particularmente os 139,403 mil hectares colhidos, contribuiu com $17,65 \%$ dos 24,358 milhões de sacas produzidas pelo Estado de Minas Gerais. É importante registrar que esse Estado sozinho produziu, em 2010, $50,67 \%$ do café brasileiro; três dos cinco municípios maiores produtores de café do Estado encontram-se na região do Alto Paranaíba: Patrocínio, Monte Carmelo e Rio Paranaíba (Minas Gerais, 2011).

O cafeeiro é uma cultura perene e pode produzir por mais de 30 anos. Em razão da competição com as plantas daninhas, sua produtividade e qualidade podem ser severamente comprometidas. Por isso, o manejo de plantas daninhas na lavoura constitui-se numa das principais práticas que oneram o custo de produção (Silva \& Ronchi, 2008). Além da redução da produtividade, que pode variar de $24 \%$ (Moraima, et al., 2000) a 92\% (Lemes et al., 2010), existem outros efeitos indiretos também prejudiciais à cultura, como, por exemplo, dificultar a colheita e tratos fitossanitários (Silva \& Ronchi, 2008). Não obstante, as plantas daninhas geralmente apresentam maior concentração de nutrientes no tecido e maior habilidade ou eficiência na absorção de nutrientes do que as plantas de café (Ronchi et al., 2007).

Logo após o transplantio no campo, as mudas de café apresentam crescimento lento e são altamente sensiveis à competição com as plantas daninhas (Ronchi et al., 2007; Lemes et al., 2010; Fialho et al., 2010). Isso ocorre porque a presença de plantas daninhas na vizinhança do cafeeiro jovem limita o acesso da cultura aos recursos do ambiente, especialmente luz e nutrientes (Radosevich et al., 1996). Vale ressaltar que é na região de solo próximo ao caule da planta, até $0,30 \mathrm{~m}$ de profundidade, que a maior parte do sistema radicular do cafeeiro (Alfonsi et al., 2005; DaMatta et al., 2009) se concentra, indicando que a ocorrência de plantas daninhas nessa região do solo é de fato indesejável e danosa ao cafeeiro. Felizmente, à medida que a idade do cafeeiro aumenta após o transplantio, as mudas tornam-se aparentemente mais tolerantes à competição com as plantas daninhas (Fialho et al., 2010).

Devido ao uso generalizado da mecanização nas lavouras de café do cerrado, estas são implantadas tradicionalmente em amplos espaçamentos (3,5 a 4,0 m entre os renques). No entanto, não há necessidade de se fazer o controle de plantas daninhas em área total, pois isso deixaria o solo completamente exposto. Por isso, o cafeeiro jovem necessita apenas que se mantenha livre de plantas daninhas uma faixa ao longo da linha de plantio, mantendo-se a vegetação na entrelinha. Muitos trabalhos recentes têm evidenciado que a manutenção da vegetação natural (ou cultivada) na entrelinha é altamente efetiva na melhoria das características físicas, químicas e biológicas do solo e da cultura (Aguilar, 2003; Shivaprasad et al., 2005; Ronchi et al., 2007; Santos et al., 2008; Alcântara et al., 2009).

No cerrado mineiro, os herbicidas, particularmente o oxyfluorfen, são amplamente utilizados para controle de plantas daninhas em pré-emergência, na linha de plantio. Todavia, ocorrem insucessos frequentes devido à intoxicação de lavouras, seja pela inadequação das doses ou da tecnologia de aplicação. O fato é que o controle químico carece de produtos seletivos para uso nessa fase da cultura (Rodrigues \& Almeida, 2005) e o uso de herbicida não seletivo em aplicação dirigida à linha de plantio (por exemplo, glyphosate) pode comprometer o status nutricional do cafeeiro jovem, devido à intoxicação das mudas por deriva (França et al., 2010), necessitando, nesse caso, de adequada e cuidadosa tecnologia de aplicação.

Alguns trabalhos foram feitos na última década buscando selecionar herbicidas para uso na cultura jovem do café (Ronchi \& Silva, 2003, 2004; Alves et al., 2010), porém há muito ainda que se pesquisar. Herbicidas como o sulfentrazone, por exemplo, que é registrado para o cafeeiro adulto (Rodrigues \& Almeida, 2005), têm potencial para uso no cafeeiro jovem. Não obstante, da mesma forma que as 
plantas de café tornam-se mais tolerantes à competição à medida que envelhecem (Fialho et al., 2010), é provável que também tornamse igualmente mais tolerantes aos herbicidas. Nesse sentido, a adequação de doses e das pontas hidráulicas utilizadas, assim como do estádio de desenvolvimento do cafeeiro após o transplantio, pode garantir o sucesso no manejo de plantas daninhas, com herbicidas em pré-emergência, em lavouras jovens na região do Alto Paranaíba. Este trabalho teve por objetivo avaliar a seletividade do oxyfluorfen e do sulfentrazone e o controle de plantas daninhas em diferentes épocas após o transplantio das mudas de café no campo.

\section{MATERIAL E MÉTODOS}

Os ensaios foram conduzidos no município de Rio Paranaíba-MG, em lavoura de Coffea arabica cv. Catuaí Vermelho IAC 144, implantada em janeiro de 2010 no espaçamento de $3,8 \times 0,65 \mathrm{~m}$, em Latossolo Vermelho. Foram realizados três experimentos, constituídos por três épocas distintas de aplicação dos herbicidas: época 1 - em fevereiro de 2010; época 2 - em abril de 2010; e época 3 - em novembro de 2010. Os ensaios foram implantados no delineamento experimental de blocos casualizados, com dez tratamentos e quatro repetições. Os blocos foram dispostos no sentido da linha de plantio. Cada parcela experimental foi constituída de oito plantas (ou 5,2 m de linha), totalizando $10,4 \mathrm{~m}^{2}$. Duas plantas nas extremidades opostas de cada parcela foram consideradas bordaduras, de forma que as quatro plantas centrais foram úteis para avaliações. A entrelinha foi manejada com roçadas, sempre que necessário. Os demais tratos culturais, incluindo adubações e controle fitossanitário, foram feitos normalmente pelo produtor.

Tanto na época 1 como na 2 foram testados os seguintes tratamentos: oxyfluorfen, aplicado nas doses de 0,36 e $0,72 \mathrm{~kg}$ i.a. ha ${ }^{-1}$, e sulfentrazone, nas doses de 0,4 e 0,6 kg i.a. ha-1; para cada herbicida/dose, testou-se a aplicação em jato dirigido (com proteção das mudas) e em área total (no topo das plantas), além das testemunhas capinada e sem capina. Os herbicidas foram aplicados com um pulverizador costal pressurizado $\mathrm{CO}_{2}$, com pressão constante de $300 \mathrm{kPa}$, munido de barra de quatro bicos tipo leque 110-03, espaçados de $0,50 \mathrm{~m}$ e com volume de calda de $185 \mathrm{~L} \mathrm{ha}^{-1}$. A faixa de aplicação foi, portanto, de 2,0 $\mathrm{m}$ sobre a linha de plantio, a 0,5 $\mathrm{m}$ do alvo. A aplicação foi feita entre 6 e $8 \mathrm{~h}$, sob temperatura e umidade relativa do ar de $21^{\circ} \mathrm{C}$ e $95 \%$ e $21{ }^{\circ} \mathrm{C}$ e $91 \%$, nas épocas 1 e 2 , respectivamente.

$\mathrm{Na}$ época 3 foram testados os mesmos herbicidas e doses dos ensaios anteriores, entretanto, como as plantas estavam com porte mais alto (o que não justificava a aplicação em área total), a aplicação foi em jato dirigido ao solo, em faixa ao lado da linha de plantio, testando-se duas formas de aplicação: barra de pulverização equipada com duas pontas de jato tipo leque plano 110-03 espaçadas de $0,50 \mathrm{~m}$ entre si (faixa aplicada de $1,0 \mathrm{~m}$ ) e barra de pulverização com uma ponta de jato tipo leque plano 110-02 (faixa aplicada de $0,5 \mathrm{~m}$ ). As duas pontas diferenciam-se pelo volume aplicado, mesmo operando na mesma pressão (300 kPa). A ponta $110-03$ possui maior orifício de abertura, proporcionando assim maior vazão, e, consequentemente, as gotas produzidas possuem maior diâmetro, o que pode reduzir substancialmente as perdas causadas pela deriva em relação às pontas 110-02. Estas, pelo fato de produzirem gotas menores, proporcionam aplicação com maior distribuição do produto sobre o alvo a ser atingido. A temperatura e a umidade relativa do ar no momento da aplicação foram de $20{ }^{\circ} \mathrm{C}$ e $91 \%$, respectivamente.

Na época 1 e na época 2 , no dia da aplicação dos tratamentos (0 DAT) e também aos 420 DAT, foram medidos a altura de plantas (distância entre o colo e a gema apical) e o diâmetro do caule (tomado a $5,0 \mathrm{~cm}$ do solo com um paquímetro digital), nas quatro plantas úteis de cada parcela experimental. Em seguida, estimou-se o incremento no crescimento das plantas nesse período, pela diferença entre os valores final e inicial de cada variável. Aos $7,15,30,45,60$ e 90 DAT avaliou-se a toxicidade causada pelos herbicidas ao cafeeiro, atribuindo-se notas percentuais de fitotoxicidade em relação à testemunha (sem aplicação), sendo zero ausência de sintomas e 100, senescência completa da planta. Aos 75 DAT, foi avaliada a porcentagem de cobertura do solo 
com plantas daninhas e, em seguida, foram feitas amostragens para identificação e quantificação da matéria seca e densidade de plantas daninhas na área. Para essas análises, adotaram-se os procedimentos descritos em Ronchi \& Silva (2004). Ainda nessas duas épocas, no dia da aplicação dos herbicidas, fezse a caracterização da área foliar média das plantas, por metodologia não destrutiva descrita por Antunes et al. (2008).

Na época 3, no dia da aplicação dos tratamentos e também aos 105 DAT, foram medidos: a altura de plantas, o diâmetro do caule e o comprimento, número de nós, número de folhas e área foliar total de dois ramos plagiotrópicos (por parcela) do terço médio do cafeeiro. Em seguida, o incremento de crescimento com base nessas variáveis foi estimado. Aos 75 DAT foi feita amostragem de plantas daninhas, para identificação e quantificação da matéria seca e da densidade dessas plantas em cada parcela.

Os dados foram submetidos à análise de variância, pelo teste $\mathrm{F}$, e as médias dos tratamentos foram comparadas pelo teste de Tukey a $5 \%$ de probabilidade. Os dados de plantas daninhas (densidade e matéria seca) foram submetidos apenas à análise descritiva. Nos ensaios 1 e 2, foram ajustadas ainda equações de regressão relacionando a porcentagem de fitotoxicidade em função das épocas de avaliação, para os tratamentos cujos sintomas de toxicidade foram visiveis. Nessas análises utilizou-se o Sistema de Análises Estatísticas e Genéticas da UFV, versão 9.0 (SAEG, 2004).

\section{RESULTADOS E DISCUSSÃO}

A principal espécie de planta daninha que ocorreu na área experimental foi Brachiaria decumbens. Aos 75 dias após a aplicação dos tratamentos (DAT), a densidade e a matéria seca dessa espécie no tratamento "testemunha sem capina" foi de 9 plantas $\mathrm{m}^{-2}$ e $31,7 \mathrm{~g} \mathrm{~m}^{-2}$ e de 6 plantas $\mathrm{m}^{-2}$ e $39,5 \mathrm{~g} \mathrm{~m}^{-2}$, para as épocas 1 e 2, respectivamente (Tabela 1). Portanto, um percentual alto da matéria seca total de plantas daninhas $(34,2 \%$ para a época 1 e $78,1 \%$ para a época 2) era composto apenas pela espécie $B$. decumbens. A prevalência dessa espécie na área experimental é perfeitamente explicada, pois, no cerrado, o café arábica tem sido comumente estabelecido em áreas anteriormente usadas para pastagens. Uma vez que $B$. decumbens é uma das espécies de Poaceae mais utilizadas para formação de pastagens no Brasil (Drumond \& Aguiar, 2005), ela tornou-se uma planta daninha muito importante na cultura do café (Souza et al., 2006). Outras espécies também ocorreram na lavoura, em menor expressão, como é o caso de Emilia fosbergii, Sida glaziovii e S. rhombifolia, na época 1 , e de S. glaziovii e S. rhombifolia, na época 2 (dados não apresentados).

Considerando que em ambas as épocas (1 e 2) foi constatada baixa porcentagem de cobertura do solo com plantas daninhas nos tratamentos com aplicação de herbicidas (Tabela 1) e que houve redução superior a 50\% na densidade e $65 \%$ na matéria seca de plantas daninhas nos tratamentos com herbicidas, em comparação à testemunha sem aplicação (Tabela 1), todos os herbicidas e doses testadas foram eficientes no controle das plantas daninhas na linha de plantio do cafeeiro, com poucas variações entre eles. Obviamente, é importante registrar que essa avaliação foi feita aos 75 DAT, praticamente no término do período esperado para efeito residual dos herbicidas. Não obstante, os herbicidas testados têm eficiência comprovada no controle em pré-emergência da maioria das espécies presentes na área experimental (Rodrigues \& Almeida, 2005).

Dos dez tratamentos avaliados, sintomas visuais de toxicidade ao cafeeiro foram constatados tanto na época 1 como na época $2 \mathrm{em}$ apenas quatro tratamentos, mais especificamente naqueles em que os herbicidas sulfentrazone (T1 e T3) e oxyfluorfen (T5 e T7) foram aplicados em área total, independentemente da dose (Tabela 2). Assim, como relatado por Ronchi \& Silva (2003), os principais sintomas visuais do oxyfluorfen em café foram queimaduras e necroses espalhadas pela lâmina foliar - sintomas esses tipicamente decorrentes da peroxidação de lipídios causada pelo oxigênio reativo (oxigênio singleto) produzido pelos inibidores da PROTOX (Hess \& Weller, 2000). Portanto, na época 1, considerando a média para as duas doses testadas, o oxyfluorfen (T5 e T7) causou fitotoxicidade de $29,4 \%$ ao longo de todo o período de 
Tabela 1 - Porcentagem de cobertura do solo com plantas daninhas na linha de plantio e densidade (plantas $\mathrm{m}^{-2}$ ) e matéria seca $\left(\mathrm{g} \mathrm{m}^{-2}\right.$ ) de Brachiaria decumbens e do total de plantas daninhas presentes nas parcelas experimentais, aos 75 dias após a aplicação dos tratamentos, em duas épocas (média \pm erro-padrão da média; $n=4$ )

\begin{tabular}{|c|c|c|c|c|c|}
\hline \multirow{3}{*}{ Tratamento* } & \multicolumn{5}{|c|}{ Variáveis } \\
\hline & \multicolumn{2}{|c|}{$\%$} & B. decumbens & \multicolumn{2}{|c|}{ Total de plantas daninhas } \\
\hline & Cobertura & Densidade & Matéria seca & Densidade & Matéria seca \\
\hline \multicolumn{6}{|c|}{ Época 1 - aplicação realizada aos 30 dias após o transplantio } \\
\hline 1 & $14,8 \pm 4,25$ & $13,0 \pm 0,24$ & $15,0 \pm 0,77$ & $15,0 \pm 0,01$ & $17,7 \pm 0,65$ \\
\hline 2 & $4,8 \pm 0,90$ & $4,0 \pm 0,20$ & $6,3 \pm 0,58$ & $13,0 \pm 0,00$ & $20,5 \pm 0,79$ \\
\hline 3 & $8,3 \pm 1,34$ & $11,2 \pm 0,47$ & $5,0 \pm 1,26$ & $9,0 \pm 0,00$ & $20,8 \pm 1,30$ \\
\hline 4 & $2,5 \pm 0,48$ & $6,0 \pm 0,43$ & $24,0 \pm 1,88$ & $14,0 \pm 1,00$ & $46,4 \pm 1,80$ \\
\hline 5 & $13,8 \pm 1,57$ & $8,0 \pm 0,20$ & $19,0 \pm 0,70$ & $16,0 \pm 0,00$ & $42,8 \pm 1,53$ \\
\hline 6 & $21,5 \pm 6,58$ & $3,0 \pm 0,24$ & $36,3 \pm 2,64$ & $8,0 \pm 0,00$ & $41,2 \pm 2,57$ \\
\hline 7 & $5,0 \pm 1,67$ & $2,0 \pm 0,14$ & $1,5 \pm 0,13$ & $11,0 \pm 0,00$ & $42,2 \pm 4,18$ \\
\hline 8 & $3,5 \pm 1,09$ & $3,0 \pm 0,24$ & $2,5 \pm 0,30$ & $7,0 \pm 0,00$ & $7,1 \pm 0,75$ \\
\hline 9 & - & - & - & - & - \\
\hline 10 & $92,5 \pm 0,72$ & $9,0 \pm 0,24$ & $31,7 \pm 0,94$ & $27,0 \pm 1,00$ & $92,6 \pm 4,05$ \\
\hline \multicolumn{6}{|c|}{ Época 2 - aplicação realizada aos 90 dias após o transplantio } \\
\hline 1 & $16,5 \pm 3,44$ & $1,0 \pm 0,13$ & $3,4 \pm 0,43$ & $2,0 \pm 0,14$ & $7,2 \pm 0,49$ \\
\hline 2 & $7,5 \pm 1,42$ & $4,0 \pm 0,35$ & $22,8 \pm 1,68$ & $7,0 \pm 0,55$ & $25,6 \pm 1,66$ \\
\hline 3 & $9,5 \pm 1,05$ & $1,0 \pm 0,13$ & $7,2 \pm 0,90$ & $4,0 \pm 0,00$ & $15,5 \pm 0,55$ \\
\hline 4 & $6,0 \pm 0,54$ & $3,0 \pm 0,24$ & $14,9 \pm 1,65$ & $10,0 \pm 0,75$ & $17,9 \pm 2,07$ \\
\hline 5 & $13,3 \pm 1,07$ & $3,0 \pm 0,24$ & $22,4 \pm 1,65$ & $5,0 \pm 0,32$ & $23,0 \pm 1,72$ \\
\hline 6 & $21,0 \pm 5,05$ & 0,0 & 0,0 & $3,0 \pm 0,24$ & $2,2 \pm 0,17$ \\
\hline 7 & $6,5 \pm 1,44$ & $4,0 \pm 0,20$ & $6,3 \pm 0,34$ & $4,0 \pm 0,20$ & $6,3 \pm 0,38$ \\
\hline 8 & $6,3 \pm 0,85$ & $2,0 \pm 0,14$ & $3,8 \pm 0,39$ & $4,0 \pm 0,20$ & $7,9 \pm 0,48$ \\
\hline 9 & - & - & - & - & - \\
\hline 10 & $88,3 \pm 0,59$ & $6,0 \pm 0,14$ & $39,5 \pm 0,81$ & $15,0 \pm 0,31$ & $50,6 \pm 1,23$ \\
\hline
\end{tabular}

* Tratamentos: (herbicida/dose em kg i.a. ha-1/forma de aplicação: área total-AT, jato dirigido-JD):1-sulfentrazone/0,4/AT; 2-sulfentrazone/ 0,4/JD; 3-sulfentrazone/0,6/AT; 4-sulfentrazone/0,6/JD; 5-oxyfluorfen/0,36/AT; 6- oxyfluorfen/0,36/JD; 7-oxyfluorfen/0,72/AT; 8oxyfluorfen/0,72/JD; 9-testemunha capinada; 10-testemunha sem capina.

avaliação. Para a época 2, a fitotoxicidade foi constante e igual a $43 \%$ quando a dose de $0,36 \mathrm{~kg} \mathrm{ha}^{-1}$ foi aplicada; para a maior dose $\left(0,72 \mathrm{~kg} \mathrm{ha}^{-1}\right)$, houve efeito quadrático da época de avaliação sobre a fitotoxicidade, mostrando redução da toxicidade a partir dos 30 DAT (Tabela 2).

Ronchi \& Silva (2004) observaram que a aplicação de oxyfluorfen $\left(0,48 \mathrm{~kg} \mathrm{ha}^{-1}\right)$ em área total, diretamente sobre as plantas de café (C. arabica cv. Catuaí Vermelho) com seis a oito pares de folhas, aos 21 dias após o transplantio para o campo, causou leve toxicidade ao cafeeiro $(26,3 \%)$, sem comprometer o crescimento das mudas, avaliado aos 130 dias após o transplantio. Nessa ocasião, obteve-se excelente controle de plantas daninhas de folhas largas (aplicação em pós-emergência inicial), à exceção de Bidens pilosa. Ronchi \& Silva (2004) constataram também, em outro experimento de campo, com o mesmo cultivar, que o oxyfluorfen aplicado na dose de $0,48 \mathrm{~kg} \mathrm{ha}^{-1}$ causou somente $16,3 \%$ de injúrias ao cafeeiro e também não prejudicou seu crescimento ao longo de 90 dias após sua aplicação, com excelente controle de plantas daninhas de folhas largas (Lipidium virginicum, Coronopus didymus e Raphanus raphanistrum) e também de Digitaria horizontalis.

Em comparação ao oxyfluorfen, o sulfentrazone (T1 e T3) causou toxicidade mais elevada ao cafeeiro, e essa resposta foi 
mais intensa na maior dose testada $(\mathrm{T} 3=$ $\left.0,6 \mathrm{~kg} \mathrm{ha}^{-1}\right)$ em comparação ao T1 $\left(0,4 \mathrm{~kg} \mathrm{ha}^{-1}\right)$, tanto na época 1 como na época 2 (Tabela 2). Além disso, a toxicidade variou de acordo com modelo quadrático ao longo do período de avaliação, ou seja, atingiu um valor máximo, decaindo ligeiramente a partir desse ponto. Dessa forma, as doses de 0,4 e 0,6 $\mathrm{kg} \mathrm{ha}^{-1}$ provocaram toxicidade estimada de 38,3 e $46,8 \%$, respectivamente, aos 53 DAA na época 1 e de 52,4 e $61,8 \%$ aos 36 DAA na época 2 (Tabela 2). Os sintomas visuais de toxicidade por sulfentrazone foram queimaduras nas folhas, manchas cloróticas e encarquilhamento das folhas apicais. Em trabalho para avaliar a seletividade de herbicidas para o cafeeiro jovem, Ronchi \& Silva (2003) constataram que o sulfentrazone causou toxicidade moderada, caracterizada pelo enrugamento e necrose nas folhas mais novas, e que aquelas que surgiram posteriormente também apresentaram sintomas idênticos, porém com menor intensidade (sem necroses). Assim como o oxyfluorfen, o sulfentrazone é inibidor da PROTOX (Hess \& Weller, 2000), o que explica as necroses observadas.

Com plantas cultivadas em vasos em casa de vegetação, Ronchi \& Silva (2003) constataram que a altura e a biomassa da parte aérea das plantas foram significativamente reduzidas em 26,7 e $16,1 \%$, respectivamente, devido à toxicidade causada pelo oxyfluorfen $\left(0,48 \mathrm{~kg} \mathrm{ha}^{-1}\right)$. Da mesma forma, constataram reduções significativas nessas variáveis de 31,6 e $46,3 \%$, respectivamente, quando o sulfentrazone foi aplicado na dose de 0,6 $\mathrm{kg} \mathrm{ha}^{-1}$. No presente trabalho, foi possivel constatar que a área foliar total média do cafeeiro, no momento da aplicação, era superior na época $2\left(744,72 \pm 2,19 \mathrm{~cm}^{2} ; n=80\right)$, em comparação à época $1\left(296,74 \pm 1,13 \mathrm{~cm}^{2} ; n=80\right.$; dados não apresentados), o que explica as maiores notas de toxicidade (independentemente do herbicida e da dose) verificadas nas plantas da época 2, em comparação às da época 1 (ver discussão anterior e resultados na Tabela 2).

Os resultados anteriores apontam para maior toxicidade à medida que esses herbicidas são aplicados em plantas com maior índice de área foliar (ou com maior idade após o transplantio), provavelmente pela maior interceptação da calda pulverizada em área total. Pelo mesmo motivo, esses resultados sugerem que esses herbicidas devem ser aplicados em jato dirigido ao solo sob a copa e não em área total. Vale ressaltar que o oxyfluorfen é registrado e recomendado para controle de plantas daninhas gramineas e de folhas largas, em aplicações em pré-emergência ou pós-emergência inicial na cultura do café após seu transplantio, em jato dirigido ao colo das plantas; o sulfentrazone, por sua vez, é recomendado apenas para cafeeiros adultos, em aplicação sob a copa das plantas (Rodrigues \& Almeida, 2005).

Tabela 2 - Equações de regressão relacionando as notas de fitotoxicidade e o número de dias (X) após a aplicação de sulfentrazone e oxyfluorfen, na época 1 e na época 2. Os tratamentos referem-se apenas àqueles em que os herbicidas foram aplicados em área total, cujos sintomas foram visíveis

\begin{tabular}{|c|c|c|}
\hline Tratamento & Equação & $\mathrm{R}^{2}$ \\
\hline \multicolumn{3}{|c|}{ Época 1 - aplicação realizada aos 30 dias após o transplantio } \\
\hline T1: sulfentrazone - 0,4 kg i.a. ha $^{-1}$ & $\hat{\mathrm{Y}}=22,445+0,626 * X-0,00619 * \mathrm{X}^{2}$ & 0,76 \\
\hline T3: sulfentrazone - 0,6 kg i.a. ha ${ }^{-1}$ & $\hat{\mathrm{Y}}=23,04+0,869^{*} \mathrm{X}-0,00793^{\mathrm{ns}} * \mathrm{X}^{2}$ & 0,69 \\
\hline T5: oxyfluorfen - 0,36 kg i.a. ha $^{-1}$ & $\hat{\mathrm{Y}}=\overline{\mathrm{Y}}=30,21$ & - \\
\hline T7: oxyfluorfen - 0,72 kg i.a. ha $^{-1}$ & $\hat{\mathrm{Y}}=\overline{\mathrm{Y}}=28,67$ & - \\
\hline \multicolumn{3}{|c|}{ Época 2 - aplicação realizada aos 90 dias após o transplantio } \\
\hline T1: sulfentrazone $-0,4 \mathrm{~kg}$ i.a. $\mathrm{ha}^{-1}$ & $\hat{\mathrm{Y}}=37,917+0,831 * \mathrm{X}-0,0119 * \mathrm{X}^{2}$ & 0,90 \\
\hline T3: sulfentrazone - 0,6 kg i.a. ha $^{-1}$ & $\hat{\mathrm{Y}}=42,05+1,1 * \mathrm{X}-0,0153 * \mathrm{X}^{2}$ & 0,94 \\
\hline T5: oxyfluorfen - 0,36 kg i.a. ha ${ }^{-1}$ & $\hat{\mathrm{Y}}=\overline{\mathrm{Y}}=43,00$ & - \\
\hline T7: oxyfluorfen - 0,72 kg i.a. ha $^{-1}$ & $\hat{\mathrm{Y}}=29,89+0,831 * \mathrm{X}-0,0139 * \mathrm{X}^{2}$ & 0,95 \\
\hline
\end{tabular}

* Significativo a $5 \%$ de probabilidade pelo teste $\mathrm{F}$, ns não significativo ( $\mathrm{P}>0,05)$. Para tratamentos, ver rodapé da Tabela 1. 
A despeito da maior toxicidade observada na época 2, resultados interessantes foram obtidos quando o aumento de crescimento das plantas foi medido com base na altura e no diâmetro do caule, após 420 DAT (Figura 1). Observa-se, portanto, nesta figura, que o crescimento das plantas não foi afetado pelos tratamentos aplicados na época 2 e que na época 1 o herbicida sulfentrazone foi o único que reduziu significativamente $(44,5 \%$; $P<0,05)$ o incremento da altura das plantas, em comparação ao da testemunha capinada, independetemente da dose, mas apenas quando foi aplicado em área total. Tomados em conjunto, esses resultados indicam que, mesmo tendo maior área foliar capaz de interceptar a calda pulverizada, a tolerância da cultura aos herbicidas é maior aos 90 do que aos 30 dias após o transplantio, para aplicação em área total. Esses resultados vêm ao encontro dos obtidos por Fialho et al. (2010), quando demonstraram que as mudas
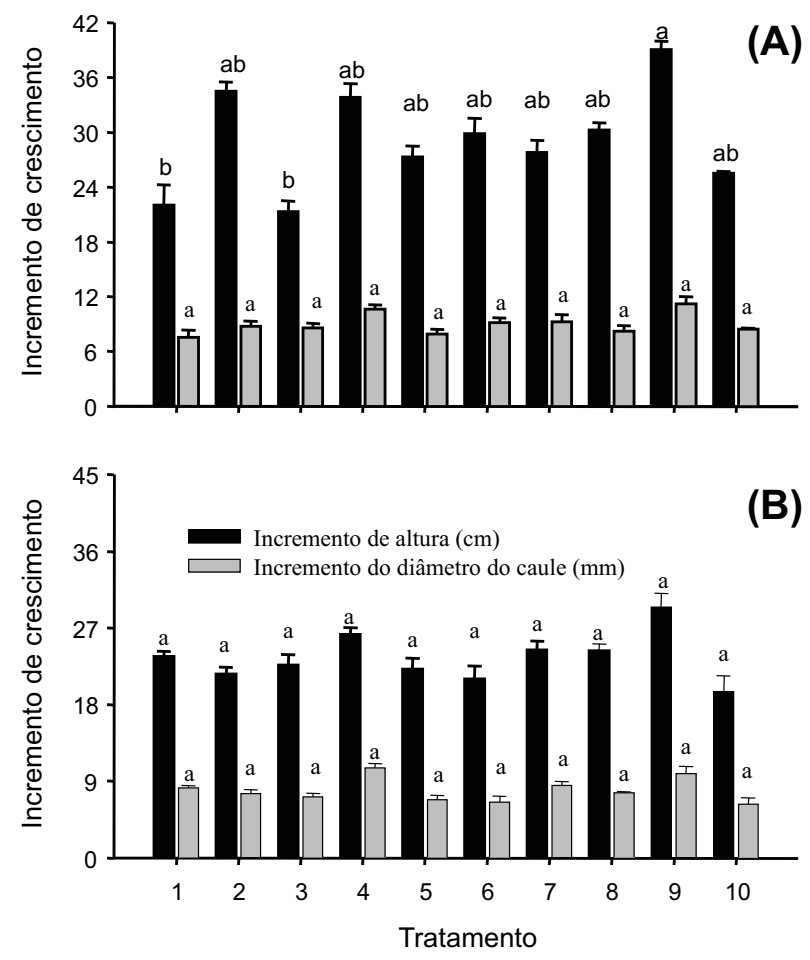

Figura 1 - Incremento de crescimento das plantas de café decorridos 420 dias da aplicação dos herbicidas, na época 1 (A) e na época 2 (B). Para tratamentos, ver rodapé da Tabela 1. Para cada variável e época de aplicação, colunas seguidas pela mesma letra não diferem entre si pelo teste de Tukey a $5 \%$ de probabilidade. de café tornam-se mais tolerantes à competição de $B$. decumbens e $B$. plantaginea se a competição se instalar mais tardiamente na cultura.

Obviamente, se a aplicação for em jato dirigido sob a copa da planta (e assim deve ser), não há restrição ao uso desses herbicidas, mesmo do sulfentrazone (desde que considerado seu comportamento no solo), pois, além de não causarem toxicidade (visual ou medida pelo crescimento) à planta, eles são eficientes no controle das principais plantas daninhas. Isso foi comprovado com a aplicação desses mesmos herbicidas e doses na época 3, aos dez meses após o transplantio. Uma vez que todos os herbicidas foram aplicados em jato dirigido, lateralmente à copa do cafeeiro, não foi constatado qualquer sintoma de fitotoxicidade. Além disso, também não foi encontrada nenhuma diferença significativa entre os tratamentos quando o incremento de crescimento foi avaliado. Observou-se, portanto, que decorridos 105 dias da aplicação, houve aumento de crescimento de $16,4 \mathrm{~cm}$ na altura das plantas de café, $5,63 \mathrm{~mm}$ no diâmetro do caule, $204,2 \mathrm{~cm}^{2}$ (ou 12 folhas) na área fotossintética, 3,83 nos nós produtivos e $20,54 \mathrm{~cm}$ no comprimento do ramo plagiotrópico (Figura 2). Esses resultados evidenciam que, do ponto de vista de seletividade, os herbicidas oxyfluorfen e sulfentrazone, nas duas doses testadas, independentemente da vazão da ponta hidráulica empregada (110-03 ou 110-02), poderiam ser utilizados em lavouras jovens para controle de plantas daninhas em pré-emergência. O produtor pode ter a opção de escolher entre duas pontas de pulverização, uma com menor potencial de deriva e outra com maior potencial de cobertura do alvo - no caso do solo, a que melhor the atende.

Esses resultados têm grande importância agronômica, visto que trazem ferramentas alternativas e mais seguras para o controle de plantas daninhas na linha de plantio do cafeeiro, em comparação ao uso de herbicidas não seletivos, que tem mostrado grande potencial de deriva e intoxicação da lavoura. Recentemente, comprovaram-se reduções dos teores de macro e micronutrientes no cafeeiro jovem pela deriva simulada de glyphosate (França et al., 2010), assim como problemas no pegamento (e queda) de frutos de café pela deriva 

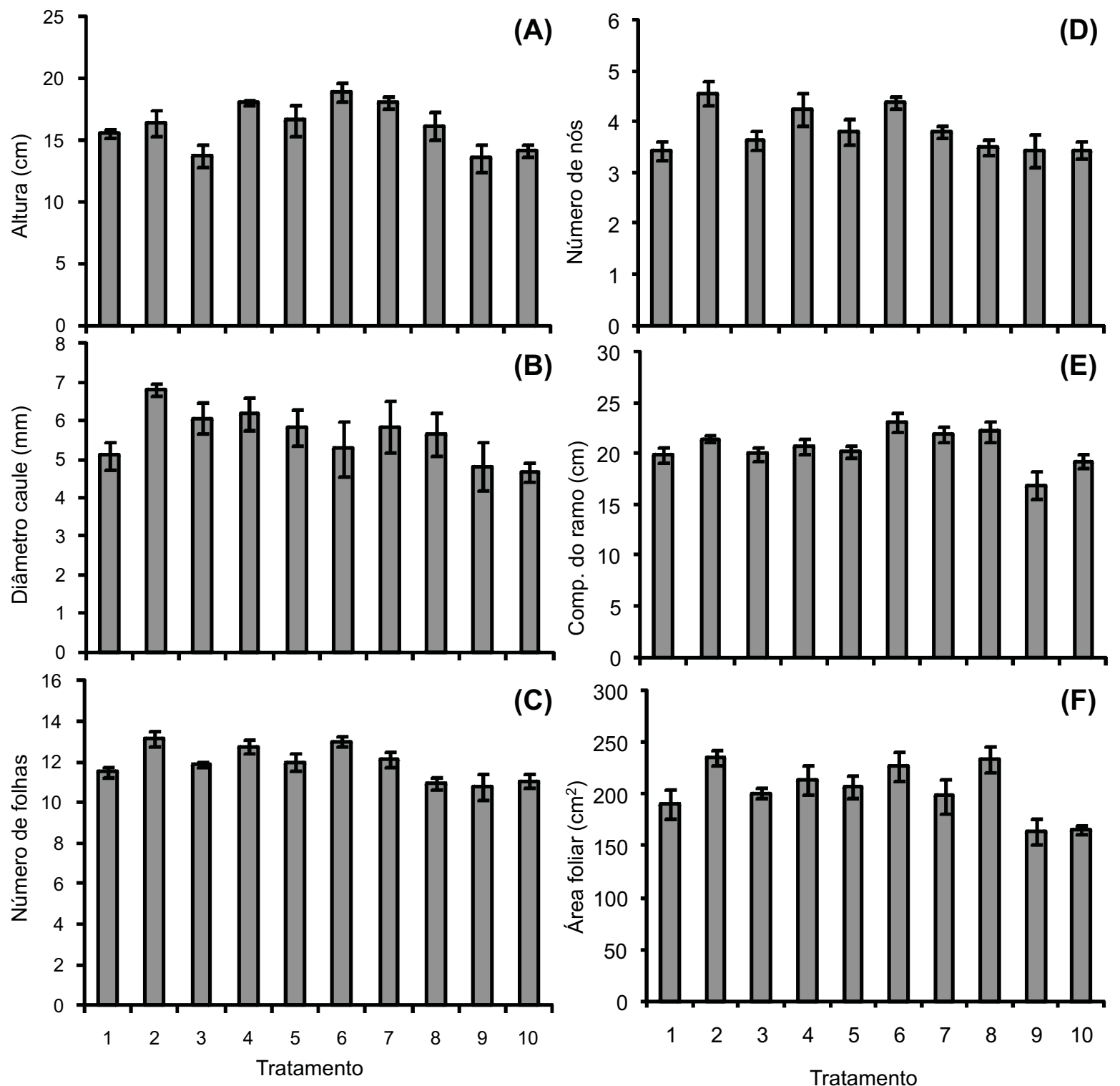

Figura 2 - Incremento de crescimento das plantas de café decorridos 105 dias da aplicação dos herbicidas, na época 3. Tratamento: (herbicida/dose em kg i.a. ha-1/ponta de pulverização): 1-sulfentrazone/0,4/P110-03; 2-sulfentrazone/0,4/ P110-02; 3-sulfentrazone/0,6/P110-03; 4-sulfentrazone/0,6/P110-02; 5-oxyfluorfen/0,36/P110-03; 6-oxyfluorfen/0,36/ P110-02; 7-oxyfluorfen/0,72/P110-03; 8-oxyfluorfen/0,72/P110-02; 9-testemnunha capinada; 10-testemunha sem capina. Não foram constatadas diferenças significativas entre as médias dos tratamentos, para nenhuma das variáveis, pelos testes F e de Tukey a 5\% de probabilidade.

de 2,4-D (Ronchi et al., 2005). Vale ressaltar que estes herbicidas, glyphosate e 2,4-D, foram e ainda são muito usados nas lavouras de café, devido à alta eficiência no controle de plantas daninhas e ao baixo custo.

Deve-se ressaltar que na época 3, assim como nas outras, a principal planta daninha que ocorreu na área experimental, com base na matéria seca, foi $B$. decumbens. Aos 75 dias após a aplicação dos herbicidas, essa espécie representava $98,8 \%$ do total de matéria seca das plantas daninhas encontradas no tratamento "testemunha sem capina" (Tabela 3). Certamente, as altas temperaturas e chuvas abundantes nessa época (Figura 3), associadas com altas irradiâncias, contribuíram para o crescimento exuberante de $B$. decumbens, 
Tabela 3 - Densidade (plantas $\left.\mathrm{m}^{-2}\right)$ e matéria seca $\left(\mathrm{g} \mathrm{m}^{-2}\right)$ de Brachiaria decumbens e do total de plantas daninhas presentes nas parcelas experimentais aos 75 dias após a aplicação dos tratamentos, na época 3 (média \pm erro-padrão da média; $n=4$ )

\begin{tabular}{|c|c|c|c|c|}
\hline \multirow{2}{*}{$\begin{array}{c}\text { Trata- } \\
\text { mento }\end{array}$} & \multicolumn{4}{|c|}{ Variáveis } \\
\cline { 2 - 5 } & \multicolumn{2}{|c|}{ B. decumbens } & \multicolumn{2}{c|}{ Total de plantas daninhas } \\
\cline { 2 - 5 } & Densidade & Matéria seca & Densidade & Matéria seca \\
\hline 1 & $1,0 \pm 0,50$ & $0,04 \pm 0,02$ & $9,0 \pm 2,06$ & $0,73 \pm 0,21$ \\
\hline 2 & $2,0 \pm 0,01$ & $8,6 \pm 2,28$ & $7,0 \pm 1,08$ & $14,73 \pm 0,38$ \\
\hline 3 & $2,0 \pm 0,58$ & $0,1 \pm 0,00$ & $11,0 \pm 2,36$ & $1,0 \pm 0,25$ \\
\hline 4 & $1,0 \pm 0,50$ & $2,5 \pm 1,23$ & $8,0 \pm 0,82$ & $5,1 \pm 1,09$ \\
\hline 5 & $2,0 \pm 0,58$ & $28,6 \pm 9,54$ & $4,0 \pm 0,82$ & $29,1 \pm 9,66$ \\
\hline 6 & $1,0 \pm 0,50$ & $11,4 \pm 5,70$ & $2,0 \pm 0,58$ & $13,6 \pm 5,42$ \\
\hline 7 & 0,0 & 0,0 & $3,0 \pm 1,50$ & $0,5 \pm 0,26$ \\
\hline 8 & $1,0 \pm 0,50$ & $1,5 \pm 0,75$ & $2,0 \pm 0,58$ & $3,2 \pm 0,92$ \\
\hline 9 & - & - & - & - \\
\hline 10 & $5,0 \pm 0,50$ & $88,4 \pm 15,64$ & $23,0 \pm 8,18$ & $89,46 \pm 15,52$ \\
\hline
\end{tabular}

* Tratamento: (herbicida/dose em kg i.a. ha ${ }^{-1} /$ ponta de pulverização): 1-sulfentrazone/0,4/P110-03; 2-sulfentrazone/0,4/ P110-02; 3-sulfentrazone/0,6/P110-03; 4-sulfentrazone/0,6/P11002; 5-oxyfluorfen/0,36/P110-03; 6-oxyfluorfen/0,36/P110-02; 7-oxyfluorfen/0,72/P110-03; 8-oxyfluorfen/0,72/P110-02; 9-testemunha capinada; 10 -testemunha sem capina.

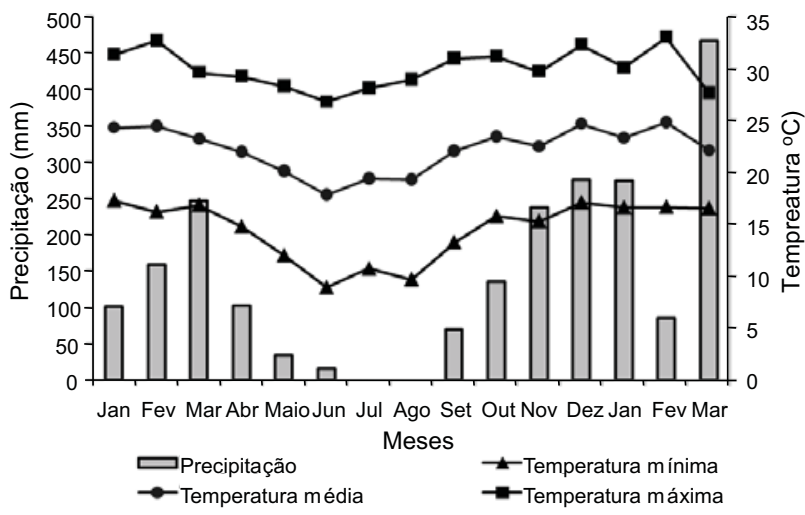

Figura 3 - Precipitação pluvial e temperatura do ar verificadas na área experimental, entre janeiro de 2010 e março de 2011.

uma vez que esta espécie tipicamente apresenta metabolismo fotossintético $\mathrm{C}_{4}$ (Ueno et al., 2005; Edwards et al., 2010). À exceção da dose de $0,36 \mathrm{~kg} \mathrm{ha}^{-1}$, todos os tratamentos herbicidas foram eficientes no controle de plantas daninhas (inclusive de $B$. decumbens), independentemente da dose e da ponta hidráulica utilizada na sua aplicação, pois reduziram a matéria seca matéria seca total de plantas daninhas em aproximadamente 95,3\%, em comparação à testemunha sem herbicida e sem capina (Tabela 3 ).
O oxyfluorfen e o sulfentrazone foram eficazes no controle de plantas daninhas em pré-emergência na linha de plantio do cafeeiro jovem, uma vez que as controlaram satisfatoriamente por um periodo superior a 60 dias. Entretanto, a aplicação desses herbicidas deve ser feita em jato dirigido sob a copa das mudas jovens, para evitar toxicidade a elas, independentemente da dose aplicada e da idade do cafeeiro após o transplantio. Caso se faça a aplicação em área total (sobre as plantas na linha de plantio), o que não é recomendável, deve-se optar pelo oxyfluorfen, e ela deve ser feita o mais tardiamente possivel após o transplantio, para não comprometer o crescimento do cafeeiro. Nesse caso, o produtor deverá adotar outras medidas de controle para o manejo de plantas daninhas na linha de plantio, imediatamente após o transplantio, a fim de evitar problemas de intoxicação das lavouras com herbicidas aplicados para controle de plantas daninhas em pré-emergência.

\section{AGRADECIMENTOS}

À Fapemig, pelo apoio financeiro ao projeto (CAG-APQ-00028-08). À Funarbe, pela concessão da bolsa de iniciação científica. À FMC, pela doação do produto. À Fazenda Transagro, pela disponibilização da área experimental.

\section{LITERATURA CITADA}

AGUILAR, V. et al. Weed vegetation response to chemical and manual selective ground cover management in a shaded coffee plantation. Weed Res., v. 43, n. 1, p. 68-75, 2003.

ALCÂNTARA, E. N. et al. Métodos de controle de plantas daninhas no cafeeiro afetam os atributos químicos do solo. Ci. Rural, v. 39, n. 3, p. 749-757, 2009.

ALFONSI, E. L. et al. Crescimento, fotossíntese e composição mineral em genótipos de Coffea com potencial para utilização como porta-enxerto. Bragantia, v. 64, n. 1, p. 1-13, 2005.

ALVES, V. M. et al. Avaliação de flumioxazin e em misturas com oxyfluorfen e clorimuron-etil em cafeeiros novos. In: CONGRESSO BRASILEIRO DA CIÊNCIA DAS PLANTAS DANINHAS, 27., 2010, Ribeirão Preto. Anais... Londrina: SBCPD, 2010.

Planta Daninha, Viçosa-MG, v. 30, n. 3, p. 607-616, 2012 
ANTUNES, W. C. et al. Allometric models for non-destructive leaf area estimation in coffee (Coffea arabica and Coffea canephora). Ann. Applied Biol., v. 153, n. 1, p. 33-40, 2008.

DaMATTA, F. M. et al. Coffee: environment and crop physiology. In: DaMATTA, F. M. (Org.). Ecophysiology of tropical tree crops. Hauppauge: Nova Science Publishers, 2009. v. 1. p. 181-216.

DRUMOND, L. C. D.; AGUIAR, A. P. A. (Eds.). Irrigação de pastagem. Uberaba: LCD Drumond, 2005. 210 p.

EDWARDS, E. J. et al. C4 grasses consortium. The origins of C4 Grasslands: integrating evolutionary and ecosystem science. Science, v. 328, n. 5978, p. 587-591, 2010.

FIALHO, C. M. T. et al. Competição de plantas daninhas com a cultura do café em duas épocas de infestação.

Planta Daninha, v. 28, p. 969-978, 2010. (Número Especial)

FRANÇA, A. C. et al. Teores de nutrientes em cultivares de café arábica submetidos à deriva de glyphosate.

Planta Daninha, v. 28, n. 4, p. 877-885, 2010.

HESS, F. D.; WELLER, S. C. Inhibitors of protoporphyrinogen oxidase: diphenyl ethers and oxadiazon. In: Herbicide action. West Lafayette: Purdue University, 2000. p. 225-243.

LEMES, L. N. et al. Weed interference on coffee fruit production during a four-year investigation after planting. Afr. J. Agric. Res., v. 5, n. 10, p. 1138-1143, 2010.

MORAIMA, G. S. et al. A contribution to determine critical levels of weed interference in coffee crops of Monagas state, Venezuela. Bioagro, v. 12, n. 3, p. 63-70, 2000.

RADOSEVICH, S. R.; HOLT, J.; GHERSA, C. Weed ecology: implication for managements. New York: John Wiley \& Sons, 1996. 589 p.

RODRIGUES, B. N.; ALMEIDA, F. S. Guia de herbicidas. 5.ed. Londrina: Edição dos Autores, 2005. 648 p.

RONCHI, C. P. et al. Effect of 2,4-dichlorophenoxyacetic acid applied as a herbicide on fruit shedding and coffee yield. Weed Res., v. 45, n. 1, p. 41-47, 2005.
RONCHI, C. P. et al. Growth and nutrient concentration in coffee root system under weed species competition. Planta Daninha, v. 25, n. 4, p. 679-687, 2007.

RONCHI, C. P.; SILVA, A. A. Tolerância de mudas de café a herbicidas aplicados em pós-emergência. Planta Daninha, v. 21, n. 3, p. 421-426, 2003.

RONCHI, C. P.; SILVA, A. A. Weed control in young coffee plantations through post-emergence herbicide application onto total area. Planta Daninha, v. 22, n. 4, p. 607-615, 2004.

SANTOS, J. C. F.; MARCHI, G.; MARCHI, E. C. S. Cobertura do solo no controle de plantas daninhas do café. Planaltina: Embrapa Cerrados, 2008. 56 p. (Documentos/ Embrapa Cerrados).

MINAS GERAIS. Secretaria de Estado de Agricultura, Pecuária e Abastecimento. Dados do Agronegócio produção agrícola: café. Disponível em: <http:// www.agricultura.mg.gov.br/dados-do-agronegocio $>$. Acesso em: 08 fev. de 2011.

SHIVAPRASAD, P. et al. Influence of soil cultivation methods in young coffee on soil moisture, weed suppression and organic matter. J. Coffee Res., v. 33, n. 1-2, p. 1-14, 2005.

SILVA, A. A.; RONCHI, C. P. Manejo e controle de plantas daninhas em café. In: VARGAS, L; ROMAN, E. S. (Org.). Manual de manejo e controle de plantas daninhas. Passo Fundo: Embrapa Trigo, 2008. p. 417-475.

SISTEMA DE ANÁLISES ESTATÍSTICAS E GENÉTICAS - SAEG. Versão 9.0. Viçosa, MG: Fundação Arthur Bernardes, 2004.

SOUZA, L. S. et al. Efeitos das faixas de controle do capimbraquiária (brachiaria decumbens) no desenvolvimento inicial e na produtividade do cafeeiro (Coffea arabica).

Planta Daninha, v. 24, n. 4, p. 715-720, 2006.

UENO, O.; YOSHIMURA, Y.; SENTOKU, N. Variation in the activity of some enzymes of photorespiratory metabolism in C4 grasses. Ann. Bot., v. 96, n. 5, p. 863-869, 2005. 